\title{
Influence of Commercial and Laboratory Diets on Growth, Body Composition, and Reproduction in the Zebrafish Danio rerio
}

\author{
L. Adele Fowler, ${ }^{1,2}$ Michael B. Williams, ${ }^{2}$ Lacey N. Dennis-Cornelius, ${ }^{2}$ \\ Susan Farmer, ${ }^{3}$ R. Jeff Barry, ${ }^{2}$ Mickie L. Powell, ${ }^{1,2}$ and Stephen A. Watts ${ }^{1,2}$
}

\begin{abstract}
The value of the zebrafish (Danio rerio) as a model organism continues to expand. In developing the model, current feeding practice in zebrafish laboratories includes the use of commercially available diets. In this study, we compared outcomes in growth, body composition, and reproduction among zebrafish fed five highly utilized commercial diets and one formulated chemically defined reference diet. Wild-type zebrafish larvae were raised on live feed until 21 days postfertilization and then fed diets for 16 weeks. All fish received a daily ration of $>5 \%$ of body weight (adjusted biweekly). Growth varied among diets throughout the feeding trial, and at study termination (week 16), significant differences among diets were observed for terminal weight gain, body condition index, body fat deposition, and reproductive outcomes. In addition, the proportion of viable embryos produced from females fed the formulated reference diet was high relative to the commercial diets. These data suggest that metabolic profiles, most likely reflecting nutrient/energy availability, utilization, and allocation, vary relative to diet in zebrafish. Undefined differences in metabolic profiles could result in erroneous predictions of health outcomes and make comparisons among laboratories more challenging. We recommend that dietary standards should be defined for zebrafish to support their common utility in biomedical research.
\end{abstract}

Keywords: zebrafish nutrition, diet, growth, body composition, study reproducibility

\section{Introduction}

$\mathbf{T}$ The ZEBRAFISH (DANIO RERIO) is a valuable model organism with applications in basic biological, environmental, aquacultural, and biomedical research. ${ }^{1-6}$ Several features, including their genetic similarity to humans, rapid development, high fecundity, ease of genetic manipulation, and relatively low maintenance costs have contributed to the growing popularity of this model system. ${ }^{1,4,7,8}$ However, a poor understanding of their nutritional requirements and the corresponding absence of a standardized reference diet have led to inconsistencies in nutrient provision and feeding practices within and among zebrafish laboratories. ${ }^{9,10}$

Lack of nutritional control among laboratories remains a concern relative to research inconsistencies that may occur. Similar concerns regarding nutritional requirements and diet standardization were addressed in rodent models several decades ago, leading to the development and adoption of standardized reference and open formulation diets of specific composition. ${ }^{11}$ As observed in mammals, specific nutrients and dietary ingredients, or the lack thereof, can potentially alter physiology, behavior, and/or molecular pathways in zebrafish, ${ }^{12-25}$ whereas other researches suggested that nutrient content of diets fed to adult zebrafish can even influence the development and health of their offspring. ${ }^{26-31}$

All these evidences suggest that for zebrafish, diet is an important environmental factor that can potentially compromise and confound outcomes related to the question of study; Therefore, a lack of nutritional control in zebrafish laboratories could affect the interpretation of both past and future research. ${ }^{32}$

At present, a wide variety of commercial diets is utilized in zebrafish research laboratories, and in some cases, include live animal supplementation (paramecia, rotifers, and brine shrimp) during early or other life stages. ${ }^{33}$ Singular and combination diets provide reasonable growth and fecundity for zebrafish culture. ${ }^{34}$

\footnotetext{
${ }^{1}$ Nutrition Obesity Research Center, University of Alabama at Birmingham, Birmingham, Alabama.

${ }^{2}$ Department of Biology, University of Alabama at Birmingham, Birmingham, Alabama.

${ }^{3}$ Animal Resources Program, University of Alabama at Birmingham, Birmingham, Alabama.
} 
Despite their widespread use, many of the formulated diets being utilized in the zebrafish community are designed for commercial aquaculture species or ornamental fish, and the qualitative and quantitative composition of nutrients and other compounds is unknown (ingredients and/or levels are closed formula). ${ }^{9,35}$ In addition, many widely used ingredients presumably included in these diets, such as soybean meal, can contain antinutritional compounds that can modify the behavior and physiology of the organism, and potentially compromise the interpretation of experimental results. ${ }^{35-37}$ The zebrafish research community will need to recognize the potential variability and unintended outcomes of using these undefined diets, a situation observed and addressed in mammalian models (primarily rats and mice) in previous decades. ${ }^{11}$

In this study, we compared metrics related to weight gain, body composition, and reproductive success among zebrafish fed five highly utilized commercial diets in zebrafish laboratories. These diets were chosen based on discussions with the Zebrafish Husbandry Association (https://zhaonline.org), and the relative use of these diets among laboratory managers. In addition, we evaluated a standard reference diet of defined ingredient and nutrient profiles, developed based on ongoing research in our laboratory. The overall purpose of this study was to comparatively evaluate the reproducibility of basic growth and reproductive outcomes of zebrafish fed formulated or live (Artemia) diets during the period of juvenile growth and onset of reproductive maturity.

\section{Materials and Methods}

\section{Diets}

The five commercial diets utilized in the study were acquired from commercial vendors and consisted of the following: Tetramin Tropical Flakes (Spectrum Brands, Blacksburg, VA), Otohime C1 (Marubeni Nisshin Feed Co. Ltd, Tokyo, Japan), Gemma Micro 300 (Skretting Zebrafish, Westbrook, ME), Ziegler Larval AP100 (Zeigler Bros, Inc., Gardners, PA), and Artemia cysts (INVE Aquaculture, Inc., Salt Lake City, UT). $\mathrm{Z} 12$ represents a formulated reference diet that was developed and manufactured in our laboratory (Table 1). Z12, Tetramin, and Otohime were ground to a size that did not exceed $300 \mu \mathrm{m}$. Proximate analysis of all diets was performed by Eurofins Scientific Laboratories, Inc. (Table 2).

Stage I Artemia nauplii were harvested at 09:00 and 17:00 hours daily. Artemia cultures were maintained in two $2 \mathrm{~L}$ brine shrimp hatching cones (Pentair Aquatic EcoSystems Inc., Apopka, FL) at a water temperature of $25^{\circ} \mathrm{C}-$ $26^{\circ} \mathrm{C}$. Cultures were set up $24 \mathrm{~h}$ before harvest, with $1.5 \mathrm{~L}$ of purified water, $15 \mathrm{~g}$ of synthetic sea salt, and $3 \mathrm{~g}$ of nondecapsulated cysts added to each cone. Before feeding, harvested nauplii were strained, rinsed, and resuspended to $200 \mathrm{~mL}$ with system water.

\section{Experimental housing and husbandry}

All procedures were approved by the UAB IACUC and adhered to standard zebrafish husbandry requirements for housing and euthanasia. All feedings were conducted twice daily at 09:00 and 17:00 hours. Zebrafish embryos (AB strain) were randomly collected from a mass spawning of males and females from the Zebrafish Research Facility at UAB.
Table 1. Dietary Composition of Z12

\begin{tabular}{|c|c|}
\hline Ingredient & $g / 100 g$ \\
\hline Fish protein hydrolysate $(82 \%)^{\mathrm{a}, \mathrm{b}}$ & 20.00 \\
\hline Casein (vita-free) $(96 \%)^{\mathrm{a}, \mathrm{c}}$ & 25.00 \\
\hline Soy protein isolate $(92 \%)^{\mathrm{a}, \mathrm{d}}$ & 5.00 \\
\hline Wheat gluten $(80 \%)^{\mathrm{a}, \mathrm{e}}$ & 7.00 \\
\hline Wheat starch & 9.60 \\
\hline Dextrin & 5.00 \\
\hline Soy lecithin & 4.00 \\
\hline Canthaxanthin & 2.31 \\
\hline Ascorbyl palmitate & 0.04 \\
\hline Vitamin premix BML-2 ${ }^{\mathrm{e}}$ & 4.00 \\
\hline Mineral mix BTm ${ }^{\mathrm{f}}$ & 3.00 \\
\hline Betaine & 0.15 \\
\hline Potassium phosphate monobasic & 1.15 \\
\hline Alginate & 5.38 \\
\hline Cholesterol & 0.12 \\
\hline Menhaden fish oil & 4.67 \\
\hline Corn oil & 2.33 \\
\hline
\end{tabular}

All ingredients are reported on an as-fed basis.

${ }^{\text {a}}$ Protein content by percentage.

${ }^{\mathrm{b}}$ The Scoular Company, Sopropeche-C.P.S.P. 90.

${ }^{\mathrm{c}}$ MP Biomedicals, cat. no. 904798.

${ }^{d}$ MP Biomedicals, cat. no. 905456. Sigma-Aldrich, cat. no. G5004.

${ }^{\mathrm{e}}$ Composition of the vitamin premix (\%): ascorbic acid, 12.5; butylated hydroxyanisole, 0.1 ; biotin, 0.1 ; cellulose, 60.0 ; calcium pantothenate, 1.5; cobalamin, 0.1; folic acid, 0.5; inositol, 18.0; nicotinic acid, 2.6; para-aminobenzoic acid, 3.0; pyridoxine hydrochloride, 0.3 ; riboflavin, 0.8 ; thiamine mononitrate, 0.5 .

${ }^{\mathrm{f}}$ Composition of the mineral premix (\%): calcium carbonate, 2.100; calcium phosphate dibasic, 73.500; citric acid, 0.227; cupric citrate, 0.046; ferric citrate, 0.558; magnesium oxide, 2.500; magnesium citrate, 0.835; potassium iodide, 0.001; potassium phosphate dibasic, 8.100; potassium sulfate, 6.800; sodium chloride, 3.060; sodium phosphate, 2.140; zinc citrate, 0.133 .

Collected embryos were transferred to Petri dishes $(n=50$ per dish) and incubated at $28.5^{\circ} \mathrm{C}$ until 5 days postfertilization (dpf). From 5 to $11 \mathrm{dpf}$, hatched larvae were polycultured in five $6 \mathrm{~L}$ static tanks ( $n=240$ larvae per tank) with the rotifer Brachionus plicatilis at a salinity of $5 \mathrm{ppt}$, and enriched with Nannochloropsis (RotiGrow Omega, Reed Mariculture). Starting at $11 \mathrm{dpf}$, each $6 \mathrm{~L}$ tank of zebrafish larvae was proffered $20 \mathrm{~mL}$ of concentrated Artemia at each feeding (equivalent to $>300$ nauplii per fish per day) until $21 \mathrm{dpf}$.

At $21 \mathrm{dpf}$, fish from all $6 \mathrm{~L}$ tanks were combined and randomly distributed into $54,2.8 \mathrm{~L}$ tanks at a density of 13 fish per tank. Each tank was then randomly assigned to one of six dietary treatments ( $n=9$ tanks per treatment). The feeding trial was initiated the following day, in which fish were fed the experimental diets for a 16-week period. All diet groups were provided a daily ration (split between the morning and evening feeding) consisting of no less than $5 \%$ body weight. To maintain this ration throughout the feeding trial, rations were adjusted for growth every 2 weeks. Fish fed the Artemia dietary treatment were provided $>500$ nauplii per fish per day (an ad libitum ration in which live Artemia were always present in the water column).

Experimental animals were maintained under a 14-h light/ 10-h dark cycle with lights turned on at 07:00 hours local time. All tanks were maintained at $28^{\circ} \mathrm{C}$ and $1500 \mu \mathrm{S} / \mathrm{cm}$ conductivity in a recirculating system (Aquaneering, Inc.), with 5.4 L exchanged from each tank per hour. Municipal tap 
Table 2. Proximate Analysis for Diets (Expressed as Percent Dry Matter)

\begin{tabular}{|c|c|c|c|c|c|c|}
\hline Component & Artemia & $Z 12$ & Tetramin & Gemma & Otohime & Zeigler \\
\hline Moisture, \% & 9.56 & 9.31 & 7.00 & 6.21 & 5.89 & 3.19 \\
\hline Crude protein, \% & 58.37 & 47.9 & 48.17 & 60.63 & 58.85 & 54.03 \\
\hline Crude fat, $\%$ & 14.66 & 12.24 & 11.01 & 19.20 & 14.08 & 14.37 \\
\hline Crude fiber, \% & 5.00 & 2.10 & 0.80 & 0.40 & 1.20 & 1.30 \\
\hline Ash, \% & 7.20 & 6.28 & 9.34 & 11.69 & 13.98 & 15.49 \\
\hline Carbohydrate, $\%^{\mathrm{a}}$ & 5.21 & 22.17 & 23.68 & 1.87 & 6.00 & 11.62 \\
\hline
\end{tabular}

Performed by Eurofins Scientific Laboratories, Inc.

${ }^{a}$ Estimated by subtraction.

water passed through mechanical filtration ( $5 \mu \mathrm{m}$ sediment filter and charcoal), reverse osmosis, and a cation/anion exchange resin (Kent Marine). Synthetic sea salts (Instant Ocean) were then added to adjust conductivity for the system water source. Sodium bicarbonate was added as needed to maintain $\mathrm{pH}$ of the system water at 7.4.

Total ammonia nitrogen, nitrite, and nitrate were measured colorimetrically once weekly (Mars Fish Care, Inc.). Water quality parameters during the experiment are given in Table 3. To help sustain adequate water quality, a minimal water exchange of $20 \%$ was performed on the recirculating system once per week, and tanks were siphoned every other day to remove any excess uneaten feed or debris. Tanks were maintained on the same recirculating system throughout the duration of the experiment; however, to reduce environmental confounding effects from noise, light, vibration, or other unidentified sources related to location, tanks were moved to a new position within the recirculating system every 2 weeks.

\section{Growth and body composition parameters}

At $21 \mathrm{dpf}$, a random subsample of fish $(n=27)$ was individually weighed and photographed to obtain initial weights and lengths. After initiation of the feeding trial, fish in each treatment tank were taken off the system, transferred to a clean $1 \mathrm{~L}$ breeding tank, and weighed and photographed as a group every 2 weeks. At the termination of the feeding trial (week 16), each fish in the study was individually weighed, photographed, and sexed. All photographs in the study were taken from above with a Nikon D70 digital camera and subsequently analyzed with NIS Elements 3.1 software to measure total body length (measured from tip of snout to the tip of caudal fin). Weights were measured to $0.001 \mathrm{~g}$, whereas total body length was measured to $0.01 \mathrm{~mm}$ using the software's ruler function.
After sex and growth measurements were recorded for each fish, female zebrafish selected for reproductive success were returned to the Aquaneering system, whereas male and female zebrafish assigned to analysis of total lipid content were subsequently killed and stored at $-80^{\circ} \mathrm{C}$ until analysis. Total lipid content was determined gravimetrically with a protocol of the Folch lipid extraction procedure ${ }^{38}$ optimized for zebrafish. A detailed description of this protocol can be found in a previous publication by Fowler et al. ${ }^{39}$ Females analyzed for total lipid content were ovariectomized before storage at $-80^{\circ} \mathrm{C}$. Weights for total lipid content and female gonads were recorded to $0.0001 \mathrm{~g}$.

- Specific growth rate (SGR) was determined with the following calculation:

$$
\mathrm{SGR}_{j-i}=\frac{\ln X_{j}-\ln X_{i}}{t_{j}-t_{i}}
$$

where $X_{i}$ and $X_{j}$ represent the mean wet body weight for each diet at the beginning and end of the period, respectively, and $t_{i}$ and $t_{j}$ represent the time in days of the beginning and end of the period, respectively.

- Body condition index (BCI) was calculated using the following formula:

$$
\mathrm{BCI}=\frac{\text { Wet body weight }(\mathrm{mg})}{\left(\text { Total body length }(\mathrm{mm})^{3}\right)} \times 100
$$

- Gonadosomatic index (GSI) was calculated for ovariectomized females using the following formula:

$$
\mathrm{GSI}=\frac{\text { Gonad weight }(\mathrm{mg})}{\text { Wet body weight }(\mathrm{mg})} \times 100 \text {. }
$$

Table 3. Water Quality Conditions During the Study Period

\begin{tabular}{lccc}
\hline Parameter & Value & Testing method & Testing frequency \\
\hline $\mathrm{pH}$ & $7.4 \pm 0.01$ & YSI Ecosense pH10 & Daily \\
Conductivity, $\mu \mathrm{S}$ & $1412.42 \pm 13.83$ & YSI Model 30 & Daily \\
Salinity, ppt & $0.69 \pm 0.01$ & YSI Model 30 & Daily \\
Temperature, ${ }^{\circ} \mathrm{C}$ & $27.42 \pm 0.03$ & YSI Model 30 & Daily \\
Nitrite, $\mathrm{mg} / \mathrm{L}$ & $0.34 \pm 0.08$ & API Test Kit & Twice weekly \\
Nitrate, mg/L & $38.18 \pm 5.76$ & API Test Kit & Twice weekly \\
TAN, mg/L & $0.1 \pm 0.02$ & API Test Kit & Twice weekly \\
Alkalinity, $\mathrm{mg} / \mathrm{L} \mathrm{CaCO}_{3}$ & $\sim 48-52$ & La Motte Test Kit & Monthly \\
\hline
\end{tabular}

Data are given as mean \pm standard error of the mean.

TAN, total ammonia nitrogen. 


\section{Reproductive success}

Ten breeding females from each treatment ( $n=5$ per tank) were reserved for evaluation of reproductive success. During the 2-week breeding period, females continued to be maintained under the same husbandry conditions and experimental feeding regime as described for the 16-week feeding trial. Females were randomly selected from each experimental tank and paired with Artemia-fed males from the UAB Nutrition Obesity Research Center's Aquatic Animal Resource Core. Each breeding pair (one male and one female) represented one breeding event. Five breeding pairs from each tank (two tanks per diet) were set up once a week for 2 weeks, resulting in 20 breeding events total per diet. Females that did not produce any eggs during the first breeding event were replaced with alternate females from the same dietary treatment for the second breeding event.

Breeding pairs were transferred to $1 \mathrm{~L}$ breeding tanks (Aquaneering) on the day before breeding at 17:00 hours with a divider separating the pair in each tank. Dividers were removed the following morning at 07:00 hours local time (when the lights turned on) and the fish were allotted a 2-h period to spawn, after which male and female fish were returned to their respective tanks. At this time, the total number of eggs produced from each breeding pair (clutch size) was counted and recorded. Collected eggs were then rinsed with system water, transferred to Petri dishes $(n=50$ eggs per dish), and incubated overnight at $28.5^{\circ} \mathrm{C}$. At $24-30 \mathrm{~h}$ postfertilization, the number of viable embryos in each clutch was manually counted under a dissecting microscope. Embryos exhibiting a stage of development consistent with the pharyngula period were considered viable. ${ }^{40}$

\section{Euthanasia}

At termination of the study, fish were killed by rapid submersion in ice-cold water with MS-222 (300 mg/L) for a minimum of $10 \mathrm{~min}$ after opercular motion had ceased. ${ }^{41}$ Carcasses were stored at $-80^{\circ} \mathrm{C}$ until analysis.

\section{Statistical modeling and analysis}

All analyses for this study were performed with RStudio Statistical Software (R Core Team, 2017, v3.4.3), and graphs were generated with the Statistical Package for Social Science (SPSS) ver.2.3 (IBM, Armonk, NY). Values of $p<0.05$ were considered statistically significant.

For continuous outcomes, data are reported as mean and standard error of the mean. All continuous data were evaluated for assumptions of normality and equal variances. No major differences in variance among dietary groups were detected for any of the outcomes. Because of the small sample size of male zebrafish, outcomes for terminal body weight, total body length, BCI, and total lipid were analyzed with male and female zebrafish combined. Each of these models adjusted for sex as a covariate and included a diet-bysex interaction term to determine whether effect modification was present.

Terminal body weight, total body length, and BCI were evaluated with a mixed-effects analysis of variance (ANOVA) to adjust for "tank" as a random effect. Mixed-effects ANOVAs were performed with help of the nlme package in R. ${ }^{42}$ Terminal body weight and BCI were log-transformed before analysis. Total lipid content was evaluated with an ANCOVA (analysis of covariance) and adjusted for body weight as a continuous covariate. GSI was evaluated with a one-way ANOVA. Any observed significant differences $(p<0.05)$ determined from the ANOVAs were further analyzed with pairwise comparisons among diets using the Tukey-Kramer post hoc test. The Tukey-Kramer post hoc test was conducted with help of the "glht" function in the multcomp package in $\mathrm{R}^{43}$

Zero-inflated regression models were selected to evaluate outcomes in spawning probability, total egg production, and embryo viability. The zero-inflated regression models consisted of two components to adjust for the presence of excessive zeros ( unsuccessful spawns) in our data. The first component used logistic regression to compare the estimated probability of a successful spawn to Artemia. The second component fitted the data for successful spawns to a discrete probability distribution to compare predicted values to Artemia. In addition to diet, week was included as a categorical covariate in all models for reproductive success.

Data for total egg production was analyzed with a hurdle negative binomial model with the pscl package in $\mathrm{R}^{44}$ The hurdle (logistic) portion of the model evaluated spawning probability, whereas the negative binomial portion of the model compared predicted values for clutch size (total egg production) from each diet to Artemia.

Our response variable for embryo viability was defined as the proportion of viable embryos to total eggs produced from each clutch. As beta regression is used to estimate proportional data values limited between zero and one, a zeroinflated beta regression (BEZI) model was selected as the most appropriate model. The beta regression portion of the BEZI model compared the predicted proportion of viable embryos from each diet to Artemia. The most parsimonious model was selected with help of the gamlss package in $\mathrm{R}$ and included the parameters nu (probability of zero viable embryos), mu (location), and sigma (scale). ${ }^{45}$

\section{Results}

No apparent differences in diet consumption were observed throughout the duration of the experiment. No behavioral or morphological features showed clinical nutritional deficits, as all fish appeared healthy. Survival was calculated at $>95 \%$ in all diet treatments. At the termination of the experiment, the sex distribution in all diets was heavily skewed toward females (Table 4).

Increases in weight gain and length over the course of the experiment were observed in all dietary treatments (Fig. 1A, B). Initially, Artemia-fed fish showed the highest rate of growth in terms of weight gain and length; however, this rate decreased after week 6 . SGR varied with diet and week, ranging from $13 \%$ to $22 \%$ body weight gain per day within the first 2 weeks of feeding, and decreasing with size to $<1 \%$ by week 14 (Fig. 2).

After controlling for the effects of sex and tank, significant differences among diet treatments were observed for body weight $\left(F_{5,44}=24.14, p<0.0001\right)$, total body length $\left(F_{5,44}=33.41, p<0.0001\right)$, and BCI $\left(F_{5,44}=8.46, p<0.0001\right)$. Mean body weight was largest in the Otohime group $(927.27 \pm 38.14 \mathrm{mg})$ than all other diets, whereas the Artemia group had the smallest mean body weight $(641.07 \pm 18.89 \mathrm{mg})$ 
Table 4. Terminal Body Weight, Length, AND Body Condition Index by Diet and SEX

\begin{tabular}{lcccc}
\hline Diet & $\mathrm{n}$ & Weight, $m g$ & Length, $m m$ & $B C I, K$ \\
\hline Artemia & & & & \\
$\quad$ Males & 19 & $432 \pm 15$ & $36.78 \pm 0.33$ & $0.87 \pm 0.02$ \\
$\quad$ Females & 73 & $696 \pm 19$ & $39.82 \pm 0.34$ & $1.09 \pm 0.02$ \\
Z12 & & & & \\
$\quad$ Males & 13 & $330 \pm 33$ & $31.92 \pm 0.88$ & $0.98 \pm 0.02$ \\
$\quad$ Females & 81 & $698 \pm 22$ & $38.01 \pm 0.42$ & $1.24 \pm 0.02$ \\
Tetramin & & & & \\
$\quad$ Males & 13 & $351 \pm 16$ & $31.78 \pm 0.49$ & $1.09 \pm 0.03$ \\
$\quad$ Females & 79 & $713 \pm 22$ & $37.08 \pm 0.37$ & $1.38 \pm 0.03$ \\
Gemma & & & & \\
$\quad$ Males & 22 & $429 \pm 11$ & $36.87 \pm 0.26$ & $0.85 \pm 0.01$ \\
$\quad$ Females & 70 & $945 \pm 30$ & $43.11 \pm 0.31$ & $1.18 \pm 0.02$ \\
Otohime & & & & \\
$\quad$ Males & 26 & $470 \pm 12$ & $36.33 \pm 0.37$ & $0.98 \pm 0.02$ \\
$\quad$ Females & 65 & $1110 \pm 32$ & $43.19 \pm 0.35$ & $1.37 \pm 0.02$ \\
Zeigler & & & & \\
$\quad$ Males & 24 & $374 \pm 20$ & $33.82 \pm 0.55$ & $0.95 \pm 0.01$ \\
$\quad$ Females & 68 & $789 \pm 23$ & $39.05 \pm 0.39$ & $1.31 \pm 0.03$ \\
\hline
\end{tabular}

Data are given as mean \pm standard error of the mean. BCI, body condition index.

(Fig. 3). Fish in the Gemma and Otohime groups had the highest mean lengths $(41.60 \pm 0.36$ and $41.22 \pm 0.42 \mathrm{~mm}$, respectively), whereas fish in the Tetramin group had the lowest $(36.32 \pm 0.37 \mathrm{~mm})$ (Fig. 4). Mean BCI was highest in the Tetramin group $(1.34 \pm 0.02)$ and lowest in the Artemia group (1.04 \pm 0.02$)$ (Fig. 5). Overall, female fish were larger than male fish (terminal body weight $\left[F_{1,496}=658.88, p<0.0001\right]$ and total body length $\left.\left[F_{1,495}=297.52, p<0.0001\right]\right)$, with a higher mean BCI $\left(F_{1,494}=492.24, p<0.0001\right)$ (Table 4$)$. Significant interaction effects of diet and sex were also observed for all three outcomes (terminal body weight $\left[F_{5,496}=4.16\right.$, $p=0.001]$, total body length $\left[F_{5,495}=3.23, p=0.007\right]$, and BCI $\left[F_{5,494}=2.81, p=0.016\right]$ ) (data not shown).

Total lipid content is given in Fig. 6 as relative lipid mass (percent of dry body mass), and as both absolute (in $\mathrm{mg}$ ) and relative lipid mass in Table 5 . Dry body weight was found to significantly co-vary with total lipid weight $(p<0.0001$, data not shown). After adjustment for dry body weight, mean lipid content differed significantly among diet groups $\left(F_{5,128}=\right.$ 7.87, $p<0.0001)$. Tetramin-fed fish had the highest mean lipid content (lipid mass, $56.48 \pm 3.41 \mathrm{mg}$; percent of dry body mass, $38.01 \% \pm 0.79 \%$ ), and Z12-fed fish had the lowest mean lipid content (lipid mass, $43.99 \pm 4.31 \mathrm{mg}$; percent of dry body mass, $30.90 \% \pm 1.05 \%$ ) (Fig. 6). Although there was no statistically significant difference in mean lipid content between male and female zebrafish $\left(F_{1,128}=0.924\right.$, $p=0.338$ ), a significant interaction effect of diet and sex was observed $\left(F_{5,128}=3.74, p=0.003\right)$.

Mean values for GSI in female zebrafish varied significantly among diet groups $\left(F_{5,85}=3.302, p=0.009\right)$ (Fig. 7). Females in the Otohime group had the highest mean GSI $(20.01 \pm 1.59)$, whereas females in the Z12 and Zeigler groups had the lowest $(13.35 \pm 0.90$ and $13.74 \pm 1.70$, respectively). Diet had variable effects on reproductive performance. Artemia-fed females had the highest percentage of successful spawns, whereas Otohime-fed females had the lowest; consequently, the probability of a successful spawn in Otohime-fed females was significantly lower than for Artemia-fed females (Tables 6 and 7). Although total egg production in Artemia-fed females did not differ from any of the other diets, embryo viability was significantly lower in Gemma-fed females (Table 7 and Figs. 8 and 9).

In addition to diet, reproductive performance was also observed to differ by week. Females were more likely to produce larger clutch sizes in week 2 ( $p<0.001$, data not shown). In contrast, no differences between weeks 1 and 2 were observed for either spawning probability or embryo viability ( $p=0.148$ and $p=0.845$, respectively; data not shown).

\section{Discussion}

Our approach represents a classical feed evaluation trial that is very straightforward in scope, but powerful in terms of recognizing the role of nutrition and the importance of the use of a standardized diet(s) for zebrafish studies. We tested commercially available diets that are commonly used in research methodology in comparison with a formulated reference diet and typical live diet. All diets tested resulted in excellent growth profiles and high survival. In discussing dietary outcomes, it is important to recognize that any differences in outcomes tested among the diets cannot be used to justify the value or efficacy of any individual diet; thus, diets cannot be ranked as "good" or "bad" in this study.

Despite excellent outcomes obtained for all diets tested, significant differences were observed in growth, body composition, and reproduction among most of the commercial diets tested in this study. Fish fed Z12, the formulated reference diet, had less fat deposition relative to body size and produced higher quality embryos, suggesting that the nutritional profile of the reference diet affected the reduction in adiposity and increased embryo production.

We strongly emphasize that these observed differences among diets are very important because these data specifically indicate that differences in outcomes related to diets do occur, even when feeding protocols are identical. Thus, the reproducibility of experimental trials is accordingly reduced. This variability ultimately can adversely complicate comparisons of research results across laboratories. Collectively, these results emphasize the need for standardized feeding practices, appropriate reporting criteria, and where appropriate, the use of chemically defined and nutritionally complete reference diets.

Growth demographics are outcomes often used to represent the response of the fish to nutrition. Throughout the course of the experiment, zebrafish grew from a late larval stage to a juvenile stage, and finally into an adult stage. Given that commercially available diets vary widely in their ingredient and nutrient content, it is likely that differential nutrient intake could influence growth and development outcomes during both the period of rapid weight gain (somatic growth) and the development of reproductive competence. In this study, weight gain data indicated that Artemia provided a growth advantage for the first 6 weeks of the feeding trial (in the juvenile stage before significant reproductive output). However, the growth rates of zebrafish fed Otohime and Gemma surpassed those for Artemia for the remaining 8 weeks of the feeding trial after the $57 \mathrm{dpf}$ timepoint. 

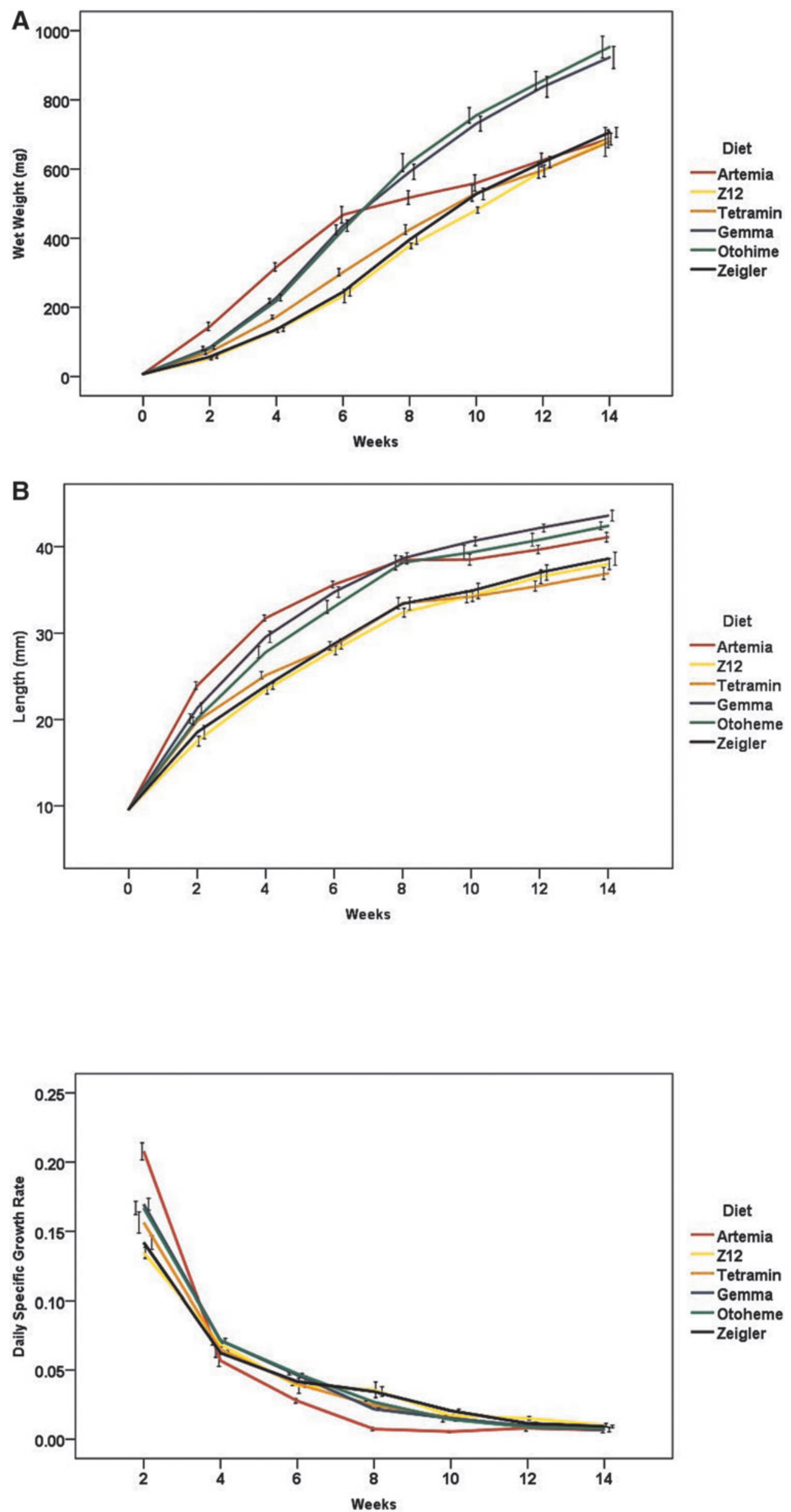

FIG. 1. Growth curves of diet groups during the feeding trial for (A) wet weight (mg) and (B) total body length (mm). Data represent mean \pm standard error of the mean. Mean individual weights and individual lengths from each tank ( $n=5$ per diet group) were recorded at 2-week intervals.
FIG. 2. Specific growth rate profiles for each diet throughout the feeding trial. Each time point represents mean \pm standard error of the mean. 
FIG. 3. Mean body weight (mg) for each diet group at the termination of the feeding trial. Error bars represent standard error of the mean. Different letters indicate betweengroup differences at $p<0.05$ as indicated by the Tukey-Kramer post hoc test.

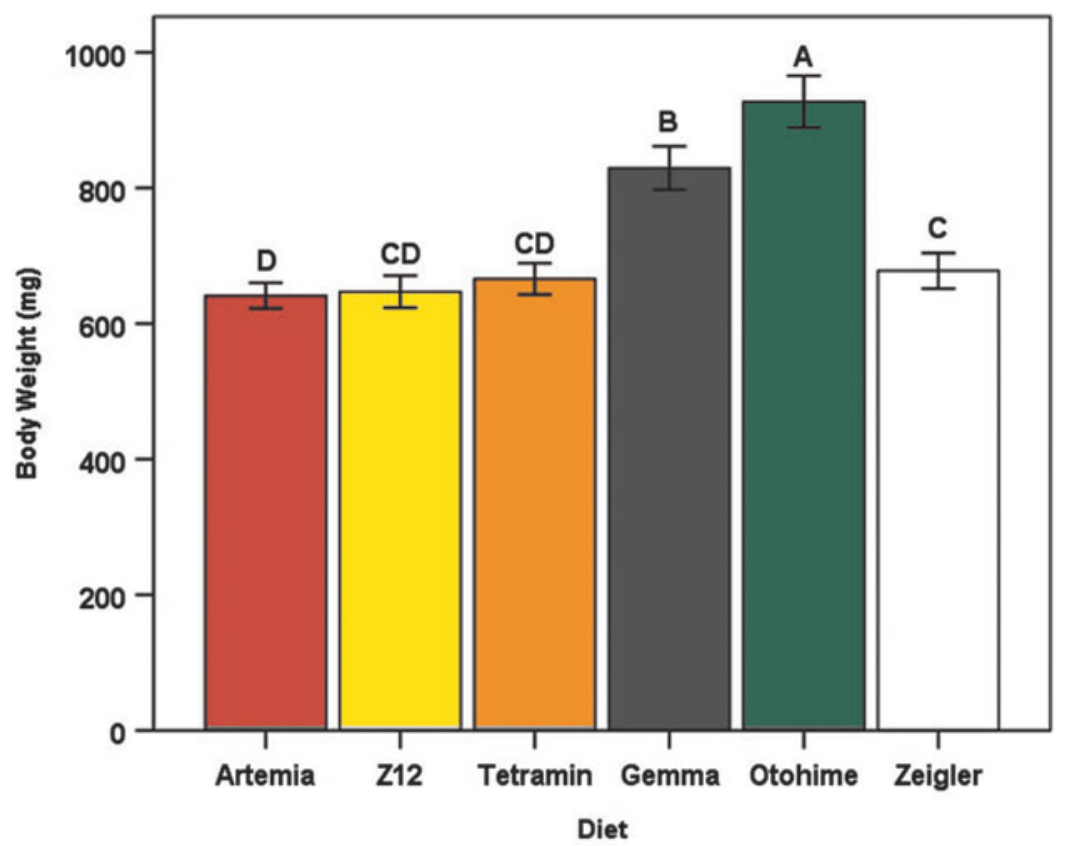

the adult stage, specific nutrients were presumably lacking or available in reduced amounts. In comparison, gut content analyses of wild zebrafish populations in south Asia indicate that the main components of their diet in the wild are zooplankton and insects in addition to a wide variety of other plant matter, ${ }^{48}$ reflecting a multisource diet. Again, it is important to point out that weight gain and SGR cannot be used solely to predict health, only the storage of energy. The differences in growth observed in our study confirm that early nutrition is important in weight gain, and that different diets produce variations in weight gain.

At the termination of the feeding trial, significant differences in weight, length, and BCI were also observed among dietary treatments. Mean terminal weights for males and

FIG. 4. Mean total body length ( $\mathrm{mm})$ for each diet group at the termination of the feeding trial. Error bars represent standard error of the mean. Different letters indicate between-group differences at $p<0.05$ as indicated by the Tukey-Kramer post hoc test.

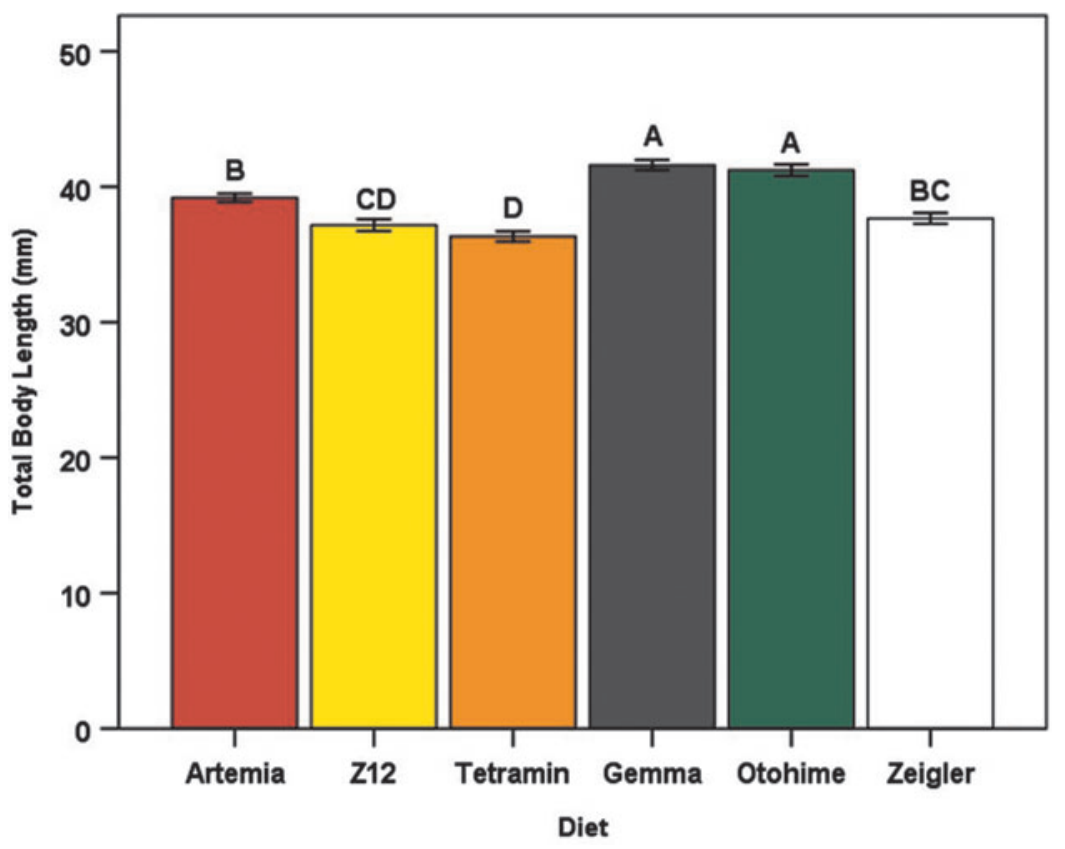




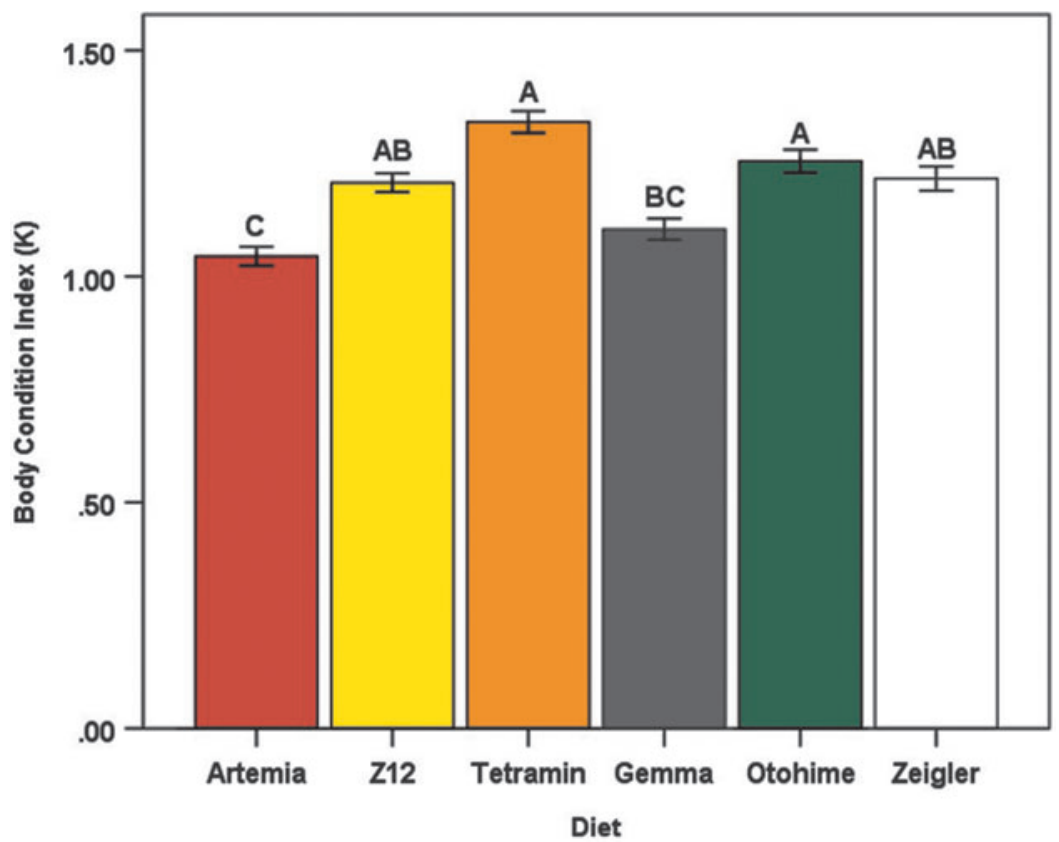

FIG. 5. Mean body condition index (K) for each diet group at the termination of the feeding trial. Error bars represent standard error of the mean. Different letters indicate between-group differences at $p<0.05$ as indicated by the Tukey-Kramer post hoc test. females combined exceeded $600 \mathrm{mg}$ for all diets. In fact, several individual females weighed in excess of $1500 \mathrm{mg}$. Weight gain was still increasing at 19 weeks of age (week 16 of the feeding trial), suggesting further growth and fat deposition potential in the zebrafish. Mean terminal weights in zebrafish fed Otohime or Gemma exceeded those fed Zeigler, Tetramin, the formulated diet, or Artemia. We emphasize that weight profiles cannot be used exclusively to establish health. We also acknowledge that the goals of many companies that produce aquaculture diets may be inherently different from those identified by a zebrafish researcher. ${ }^{35}$ For example, most aquaculture diets are formulated to produce a fish that grows rapidly, often using metrics related to meat production and not necessarily long-term health. ${ }^{35}$ Possible long-term effects of rapid weight gain have not been evaluated in zebrafish populations.

BCI is traditionally considered an indicator of health in wild fish populations, but it should be interpreted cautiously as an assessment of zebrafish health. In zebrafish, the BCI varies between males and females (because of sex-specific anatomical differences), and it should therefore be exclusively compared within a specific sex. In addition, zebrafish consuming commercial and formulated laboratory diets that are nutrient dense diets, potentially lead to an overconsumption of specific nutrients and energy, thereby contributing to a high BCI. Thus, a high BCI may reflect a health

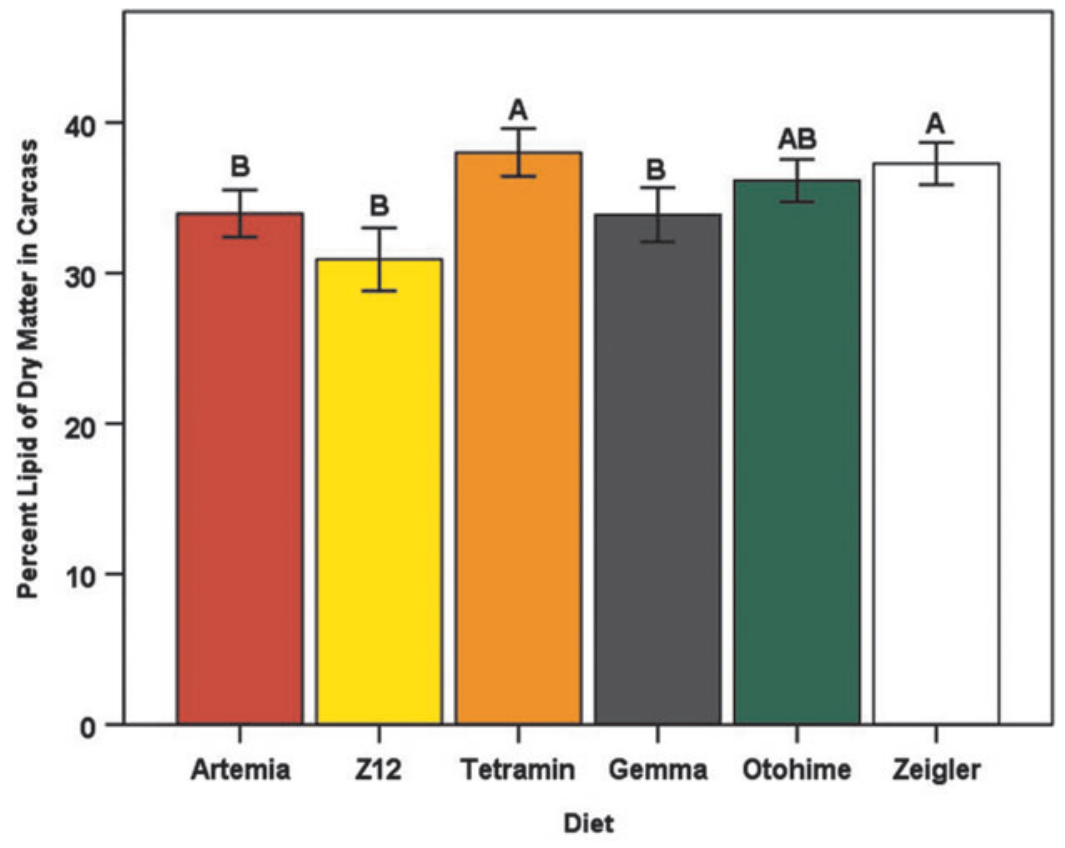

FIG. 6. Mean lipid content (total lipid weight as a percent of dry body weight) for each diet group at the termination of the feeding trial. Error bars represent standard error of the mean. Data were analyzed as total lipid mass and adjusted for dry body weight (ANCOVA). Different letters indicate between-group differences within each sex at $p<0.05$ as indicated by the TukeyKramer post hoc test. ANCOVA, analysis of covariance. 
Table 5. Total Lipid Content by Diet and SeX

\begin{tabular}{lrcc}
\hline Diet & $\mathrm{n}$ & $\begin{array}{c}\text { Total Lipid } \\
\text { Mass, } m g\end{array}$ & $\begin{array}{c}\text { As percent } \\
\text { of dry body mass }\end{array}$ \\
\hline $\begin{array}{l}\text { Artemia } \\
\quad \text { Males }\end{array}$ & 9 & $49.8 \pm 3.7$ & $35.5 \pm 1.2$ \\
$\quad$ Females & 15 & $58.9 \pm 3.4$ & $33.0 \pm 1.0$ \\
Z12 & & & \\
$\quad$ Males & 6 & $20.9 \pm 2.1$ & $27.1 \pm 1.5$ \\
$\quad$ Females & 15 & $50.5 \pm 4.1$ & $31.6 \pm 1.4$ \\
Tetramin & & & \\
$\quad$ Males & 6 & $42.7 \pm 4.7$ & $38.6 \pm 1.6$ \\
$\quad$ Females & 15 & $62.0 \pm 3.5$ & $37.8 \pm 0.9$ \\
Gemma & & & \\
$\quad$ Males & 10 & $38.4 \pm 2.3$ & $30.5 \pm 1.2$ \\
$\quad$ Females & 15 & $79.6 \pm 4.0$ & $36.1 \pm 0.9$ \\
Otohime & & & \\
$\quad$ Males & 13 & $47.6 \pm 3.7$ & $33.6 \pm 1.4$ \\
$\quad$ Females & 15 & $101.9 \pm 3.5$ & $37.5 \pm 0.6$ \\
Zeigler & & & $33.7 \pm 1.0$ \\
$\quad$ Males & 11 & $35.1 \pm 1.7$ & $39.2 \pm 0.7$ \\
$\quad$ Females & 15 & $76.1 \pm 4.9$ & \\
\hline Data are given as mean \pm standard error of the mean.
\end{tabular}

outcome similar to a high body mass index (BMI) used in human populations. A high BMI is reflective of obese phenotypes and concomitant with additional comorbidities. There may be value in using BCI combined with other outcomes to evaluate health in zebrafish.

Zebrafish are considered an excellent model for the study of human pathologies including obesity, as they share many traits with mammals. ${ }^{1}$ Fish will store fat in visceral, subcutaneous, and intramuscular regions. ${ }^{49,50}$ It is possible that some diets designed for other species may not be appropriate for zebrafish, containing excessive energy relative to protein. A consequence of feeding these diets could be excessive fat deposition and fat stored in the liver or other tissues and conditions could negatively impact health. ${ }^{51,52}$ Excessive fat deposition may also affect fecundity of the fish, with possible epigenetic effects on F1 and later progenies derived from these populations. ${ }^{53-55}$ Although fat content of zebrafish collected from wild populations has not been evaluated, the proportional level of fat in most healthy warm water fish varies from $15 \%$ to $22 \%$. $^{47}$

In this study, mean carcass fat content ranged from $27 \%$ to $38.6 \%$ of dry matter in males and $32.8 \%$ to $38.4 \%$ in females. Despite the ovaries being removed, fat content of the carcass in females was still surprisingly high. Based on the levels of mean carcass fat content, we suggest that zebrafish would be ranked as obese in all diet treatments, although the level of adiposity varied with diet. Observations indicate that excess food was always available at the bottom of the tank. In the absence of established feed management practices, we hypothesize that zebrafish could overconsume available feed, leading to excessive body fat storage. As each treatment received only one diet, it is also possible that zebrafish overconsumed their respective diets so they could consume a targeted amount of a specific nutrient. ${ }^{56}$

Our results indicate that we need to focus on feed management as a strategy to enhance nutrition. This goal could be accomplished by determining an optimal daily ration or feeding a reduced ration at a subsatiation level. In addition, if zebrafish are attempting to target the level of a specific nutrient, then both the nutrient and target level need to be identified. Recent ARRIVE guidelines do not address specifics related to feeding, indicating that additional work is needed in this area. ${ }^{57}$

Another primary goal of zebrafish husbandry is the development of breeding stocks for embryo production. Gametogenesis and spawning require proper nutrition for the production and release of quality gametes; therefore, we would expect healthy fish to produce numerous viable gametes leading to successful production of viable progeny.

Dietary essential fatty acid (EFA) composition has been found to significantly impact fecundity and larvae quality in
FIG. 7. Mean GSI of female zebrafish for each diet group at the termination of the feeding trial. Error bars represent standard error of the mean. Different letters indicate between-group differences within each sex at $p<0.05$ as indicated by the TukeyKramer post hoc test. GSI, gonadosomatic index.

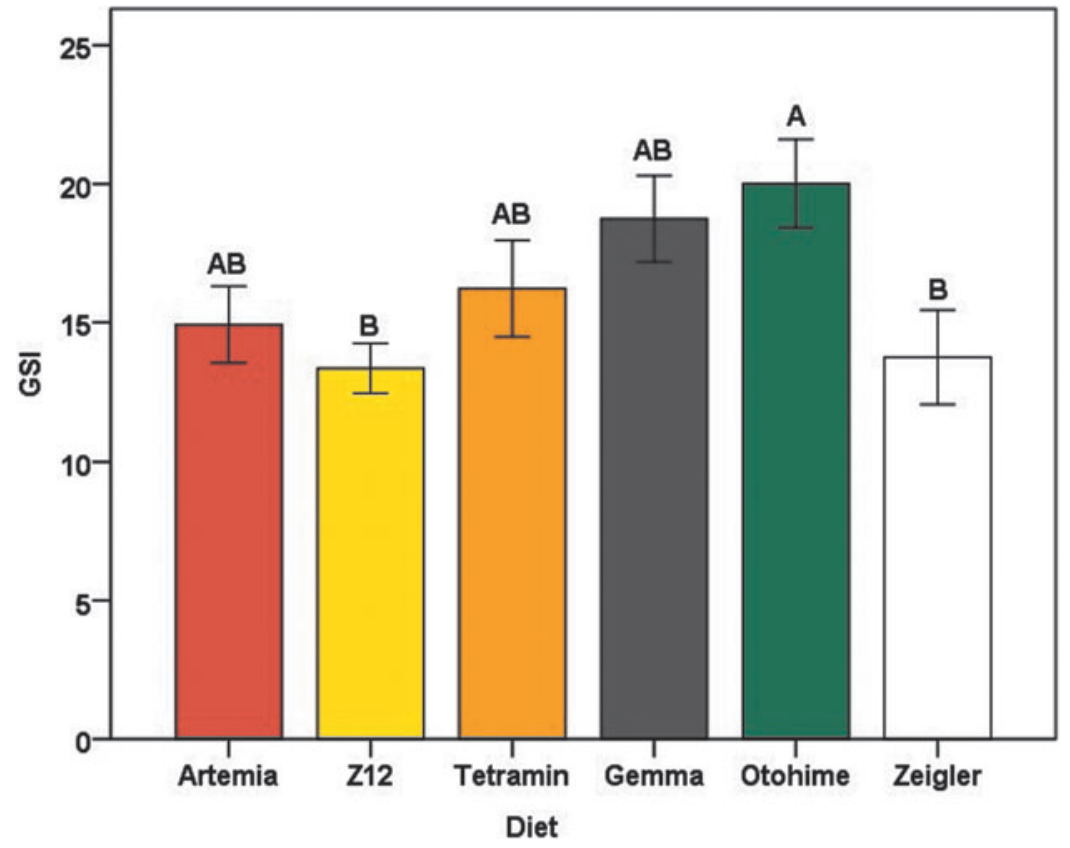


Table 6. Spawning Success By Diet

\begin{tabular}{lcc}
\hline Diet & No. of successful atotal $^{\text {a }}$ & Proportion successful \\
\hline Artemia & $20 / 20$ & 1.00 \\
Z12 & $19 / 20$ & 0.95 \\
Tetramin & $14 / 20$ & 0.70 \\
Gemma & $18 / 20$ & 0.90 \\
Otohime & $12 / 19$ & $0.63^{\mathrm{b}}$ \\
Zeigler & $16 / 19$ & 0.84
\end{tabular}

${ }^{a}$ Number of breeding events in which eggs were released by the female.

${ }^{\mathrm{b}}$ Statistically significant from Artemia.

spawning zebrafish ${ }^{26,27,58}$; we hypothesize that the relatively high historical reproductive success of Artemia could be attributed to having the most favorable dietary EFA profile for health and reproduction. For this reason, Artemia was also used as the basis of comparison in all analyses for reproductive success.

Dietary EFA deficiencies could also be responsible for the inverse correlation between GSI and both probability of egg production and viable embryos observed in our study. The influences of dietary n-6 and n-3 fatty acid content on mechanisms affecting egg release have been well established. $^{59-61}$ These EFAs regulate and are precursors to prostaglandins, which are compounds that significantly affect male spawning behavior and ovulation in zebrafish and other fish species. ${ }^{61,62}$ Therefore, EFA deficiencies could result in a

Table 7. Comparisons in Reproductive Success to Artemia-Fed Females

\begin{tabular}{lrc}
\hline Outcome & Coefficient (standard error) & $\mathrm{p}$ \\
\hline Spawning success $^{\mathrm{a}}$ & & \\
Z12 & $-1.112 \mathrm{e}-08(1.456)$ & 1.000 \\
Tetramin & $-2.131(1.143)$ & 0.062 \\
Gemma & $-0.754(1.270)$ & 0.554 \\
Otohime & $-2.657(1.130)$ & 0.019 \\
Zeigler & $-0.754(0.522)$ & 0.148 \\
Total egg production ${ }^{\mathrm{b}}$ & & \\
Z12 & $0.099(0.236)$ & 0.674 \\
Tetramin & $0.058(0.254)$ & 0.821 \\
Gemma & $0.162(0.237)$ & 0.495 \\
Otohime & $-0.086(0.273)$ & 0.754 \\
Zeigler & $0.059(0.251)$ & 0.813 \\
Embryo viability & & \\
Z12 & $-0.121(0.344)$ & 0.718 \\
Tetramin & $-0.068(0.367)$ & 0.853 \\
Gemma & $-0.747(0.359)$ & 0.040 \\
Otohime & $-0.658(0.357)$ & 0.068 \\
Zeigler & $-0.242(0.332)$ & 0.468 \\
\hline
\end{tabular}

Negative coefficients represent a lower spawning probability or lower predicted value relative to Artemia, whereas positive coefficients represent a higher spawning probability or higher predicted value.

Dependent variables: spawning success $=$ probability of successful spawn; total egg production = predicted mean clutch size; embryo viability $=$ mean predicted proportion of viable embryos within a clutch.

${ }^{\mathrm{a}}$ Results from logistic regression (hurdle) component of hurdle negative binomial model.

${ }^{5}$ Results from negative binomial regression component of hurdle negative binomial model.

${ }^{\mathrm{c}}$ Results from beta regression component of zero-inflated beta regression model. dysregulated signaling pathway that prevents the release of eggs during spawning, resulting in a large mass of stored eggs with degraded quality. Although commercially available diets provide reasonable fecundity for zebrafish culture, we hypothesize that dietary EFA requirements will need to be determined specifically for male and female zebrafish to promote optimal reproductive success and health of both zebrafish and their offspring.

An additional objective of our study was to compare the commercial diets with a formulated reference diet (Z12) prepared in our laboratory. Protein levels utilized in the Z12 diet were determined from a previous study in our laboratory that evaluated protein intake in the zebrafish ${ }^{63}$; however, additional studies will be needed to evaluate other macronutrient and micronutrient requirements. The proximate composition of Z12 supported reasonable growth in this study. Of interest, our results indicated that Z12 was comparable with Artemia in terms of both egg production from females and embryo viability. These findings provide additional supporting evidence that an open formulation, chemically defined diet can be successfully used in zebrafish laboratories.

Use of a defined reference diet can also serve as a prerequisite for identifying the specific daily nutritional requirements in zebrafish that promote health and reproduction in this model organism. As we gain more knowledge of their daily nutritional requirements over time, the reference diet could be adapted or optimized for specific studies. This need has become even more essential in recent years, as there is significant research expanding the use of adult zebrafish for preclinical research into various diseases. ${ }^{2}$

The appropriate application of statistical methods is essential for understanding the contributions that specific nutrients and ingredients have on zebrafish health. As observed with our data for total egg production, discrete variables are generally not normally distributed and are more likely to have excessive variation (overdispersion). Therefore, the statistical methods for analysis of discrete measures of reproductive success must be carefully considered, given that parametric tests may not always be appropriate. Fitting embryo counts to regression models with discrete probability distributions (i.e., Poisson or negative binomial, depending on the degree of variation) will be more likely to provide a better description of the data.

Zero-inflated models, such as those used in our study to analyze both total egg production and embryo viability, are also useful for datasets characterized by a large number of zero counts. Zero-inflated regression models are particularly helpful in the evaluation of embryo viability data, as they exclude unsuccessful spawning events from the analysis. In future studies, selection of appropriate models to evaluate outcomes in reproductive success will allow us to reach the most accurate conclusions regarding the effects of a specific nutrient or ingredient on zebrafish health.

This study indicates that experimental variability can arise from utilizing an assortment of defined and undefined diets in zebrafish laboratories. A proximate analysis revealed considerable differences in crude protein, fat, fiber, and carbohydrate content among the diets tested in this study, indicating substantial variation in nutrient profiles among these feeds. Our data, along with results from previous studies, ${ }^{64-68}$ clearly demonstrate that variations in dietary ingredients and corresponding nutrient composition among commercially available 
FIG. 8. Box and whisker plot representing eggs produced from successful spawns for each diet group. The line through the center of the box represents the median. The bottom and top of the boxes represent the first and third quartiles, respectively. The upper and lower whiskers represent data within 1.5 IQR of the third quartile and first quartile, respectively. No statistically significant differences in egg production from the Artemia group were observed. IQR, interquartile ranges.

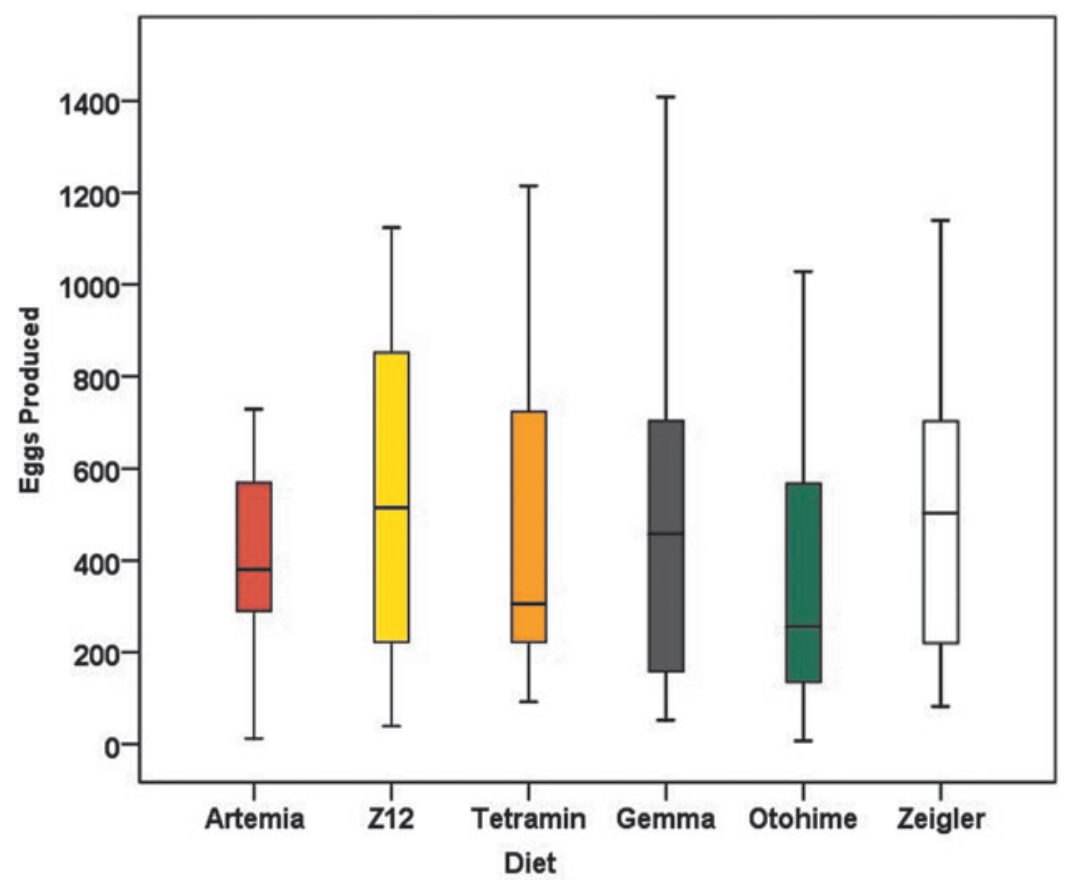

diets can affect growth, reproduction, disease, and consequently, response to experimental manipulation in zebrafish. In studies where outcomes of interest may be affected by the content of specific nutrients or presence of antinutritional compounds, a detailed reporting of the ingredient and nutrient composition of laboratory animal diets must be provided.

In addition the zebrafish research community should also promote use of open formulation, chemically defined diets. The availability of quality commercial diets has allowed zebrafish to become one of the premier animal models in the study of human health. Commercial diets are also valuable for maintaining large populations of zebrafish under general holding protocols. However, many of these diets have closed formulations and the quantitative ingredient compositions are not publicly available. ${ }^{69}$ The use of undefined commercial diets in zebrafish research can confound and impede the study of mechanisms by which nutrition influences experimental outcomes. Given the utility of the zebrafish as an animal model for human health and coupled with the continued investment and utilization of research dollars at many different institutions, it is imperative that we develop diets and feed management protocols to enhance the valuable contribution of this important model.
FIG. 9. Box and whisker plot depicting the ratio of viable embryos to total embryos produced per female zebrafish from each diet. Unsuccessful breeding events (no eggs produced) were excluded from this analysis. The line through the center of the box signifies the median. The bottom and top of the boxes represent the first and third quartiles, respectively. The upper and lower whiskers represent data within 1.5 IQR of the third quartile and first quartile, respectively. The circles represent outliers. Statistical significance from Artemia $(P<0.05)$ was evaluated with a zero-inflated beta regression model, and is represented as a*.

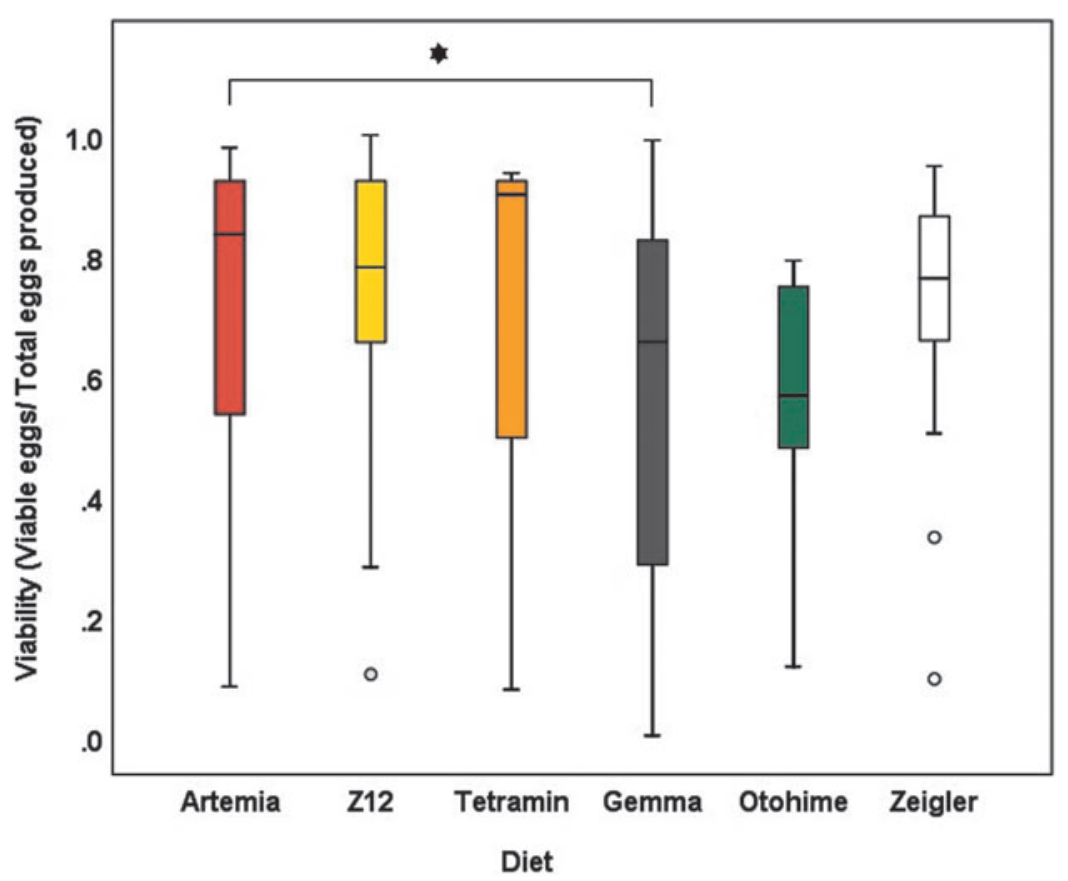




\section{Acknowledgments}

The authors acknowledge Drs. Robert Makowsky and John Dawson for their review of the statistical analyses and results, and Dr. David Allison for his support on the project. The authors also acknowledge the Nutrition Obesity Research Center Aquatic Animal Models Core and members of the Watts laboratory for their assistance with zebrafish diet manufacture, husbandry, and data collection.

This study was supported by research grants from the American College of Laboratory Animal Medicine Foundation (2011905) and the National Institute of Diabetes and Digestive and Kidney Diseases (award no. P30DK056336). The study was also supported in part by a training grant from the National Heart, Lung, and Blood Institute (award no. T32HL105349). The content is solely the responsibility of the authors and does not necessarily represent the official views of the National Institute of Diabetes and Digestive and Kidney Diseases, the National Heart, Lung, and Blood Institute, or the National Institutes of Health.

\section{Disclosure Statement}

No competing financial interests exist.

\section{References}

1. Oka T, Nishimura Y, Zang L, Hirano M, Shimada Y, Wang $\mathrm{Z}$, et al. Diet-induced obesity in zebrafish shares common pathophysiological pathways with mammalian obesity. BMC Physiol 2010;10:1-13.

2. Gut P, Reischauer S, Stainier DYR, Arnaout R. Little fish, big data: zebrafish as a model for cardiovascular and metabolic disease. Physiol Rev 2017;97:889-938.

3. Ulloa PE, Medrano JF, Feijoo CG. Zebrafish as animal model for aquaculture nutrition research. Front Genet 2014;5:313.

4. Seth A, Stemple DL, Barroso I. The emerging use of zebrafish to model metabolic disease. Dis Model Mech 2013;6: 1080-1088.

5. Heckler K, Kroll J. Zebrafish as a model for the study of microvascular complications of diabetes and their mechanisms. Int J Mol Sci 2017;18:2002.

6. Dai YJ, Jia YF, Chen N, Bian WP, Li QK, Ma YB, et al. Zebrafish as a model system to study toxicology. Environ Toxicol Chem 2014;33:11-17.

7. Gomez-Requeni P, Conceicao LE, Olderbakk Jordal AE, Ronnestad I. A reference growth curve for nutritional experiments in zebrafish (Danio rerio) and changes in whole body proteome during development. Fish Physiol Biochem 2010;36:1199-1215.

8. Hölttä-Vuori M, Salo Veijo TV, Nyberg L, Brackmann C, Enejder A, Panula $\mathrm{P}$, et al. Zebrafish: gaining popularity in lipid research. Biochem J 2010;429:235-242.

9. Watts SA, Powell M, D'Abramo LR. Fundamental approaches to the study of zebrafish nutrition. ILAR J 2012; 53:144-160.

10. Lawrence C. The husbandry of zebrafish (Danio rerio): a review. Aquaculture 2007;269:1-20.

11. Report of the American Institute of Nutrition Ad Hoc Committee on Standards for Nutritional Studies. J Nutr 1977;107:1340-1348.

12. Meguro S, Hasumura T, Hase T. Body fat accumulation in zebrafish is induced by a diet rich in fat and reduced by supplementation with green tea extract. PLoS One 2015;10: e0120142.
13. Thomas JK, Janz DM. Dietary selenomethionine exposure in adult zebrafish alters swimming performance, energetics and the physiological stress response. Aquat Toxicol 2011; 102:79-86.

14. Meinelt T, Schulz C, Wirth M, Kürzinger H, Steinberg C. Correlation of diets high in n-6 polyunsaturated fatty acids with high growth rate in zebrafish (Danio rerio). Comp Med 2000;50:43-45.

15. O'Brine TM, Vrtelova J, Snellgrove DL, Davies SJ, Sloman KA. Growth, Oxygen consumption, and behavioral responses of Danio rerio to variation in dietary protein and lipid levels. Zebrafish 2015;12:296-304.

16. Carnovali M, Luzi L, Terruzzi I, Banfi G, Mariotti M. Metabolic and bone effects of high-fat diet in adult zebrafish. Endocrine 2018;61:317-326.

17. Vargas R, Vasquez IC. Effects of overfeeding and high-fat diet on cardiosomatic parameters and cardiac structures in young and adult zebrafish. Fish Physiol Biochem 2017;43: 1761-1773.

18. McDougall M, Choi J, Magnusson K, Truong L, Tanguay R, Traber MG. Chronic vitamin E deficiency impairs cognitive function in adult zebrafish via dysregulation of brain lipids and energy metabolism. Free Radic Biol Med 2017; 112:308-317.

19. Leigh SC, Nguyen-Phuc B-Q, German DP. The effects of protein and fiber content on gut structure and function in zebrafish (Danio rerio). J Comp Physiol B 2018;188:237-245.

20. Falcinelli S, Rodiles A, Hatef A, Picchietti S, Cossignani L, Merrifield DL, et al. Dietary lipid content reorganizes gut microbiota and probiotic L. rhamnosus attenuates obesity and enhances catabolic hormonal milieu in zebrafish. Sci Rep 2017;7:5512.

21. de Vareilles M, Conceicao LE, Gomez-Requeni P, Kousoulaki K, Richard N, Rodrigues PM, et al. Dietary lysine imbalance affects muscle proteome in zebrafish (Danio rerio): a comparative 2D-DIGE study. Mar Biotechnol (NY) 2012;14:643-654.

22. Ulloa PE, Pena AA, Lizama CD, Araneda C, Iturra P, Neira $\mathrm{R}$, et al. Growth response and expression of muscle growthrelated candidate genes in adult zebrafish fed plant and fishmeal protein-based diets. Zebrafish 2013;10:99-109.

23. Lebold KM, Lohr CV, Barton CL, Miller GW, Labut EM, Tanguay RL, et al. Chronic vitamin E deficiency promotes vitamin $\mathrm{C}$ deficiency in zebrafish leading to degenerative myopathy and impaired swimming behavior. Comp Biochem Physiol Toxicol Pharmacol 2013;157:382-389.

24. Yossa R, Sarker PK, Karanth S, Ekker M, Vandenberg GW. Effects of dietary biotin and avidin on growth, survival, feed conversion, biotin status and gene expression of zebrafish Danio rerio. Comp Biochem Physiol B Biochem Mol Biol 2011;160:150-158.

25. Gómez-Requeni P, de Vareilles M, Kousoulaki K, Jordal A-EO, Conceição LE, Rønnestad I. Whole body proteome response to a dietary lysine imbalance in zebrafish Danio rerio. Comp Biochem Physiol D Genomics Proteomics 2011;6:178-186.

26. Araújo F, Costa D, Machado M, Paulino R, Okamura D, Rosa P. Dietary oils influence ovary and carcass composition and embryonic development of zebrafish. Aquacult Nutr 2017;23:651-661.

27. Nowosad J, Kucharczyk D, Targońska K. Enrichment of zebrafish Danio rerio (Hamilton, 1822) diet with polyunsaturated fatty acids improves fecundity and larvae quality. Zebrafish 2017;14:364-370. 
28. Newman T, Jhinku N, Meier M, Horsfield J. Dietary intake influences adult fertility and offspring fitness in zebrafish. PLoS One 2016;11:e0166394.

29. Skjærven KH, Jakt LM, Fernandes JM, Dahl JA, Adam A$\mathrm{C}$, Klughammer J, et al. Parental micronutrient deficiency distorts liver DNA methylation and expression of lipid genes associated with a fatty-liver-like phenotype in offspring. Sci Rep 2018;8:3055.

30. Beaver LM, Nkrumah-Elie YM, Truong L, Barton CL, Knecht AL, Gonnerman GD, et al. Adverse effects of parental zinc deficiency on metal homeostasis and embryonic development in a zebrafish model. J Nutr Biochem 2017; 43:78-87.

31. Miller GW, Truong L, Barton CL, Labut EM, Lebold KM, Traber MG, et al. The influences of parental diet and vitamin $\mathrm{E}$ intake on the embryonic zebrafish transcriptome. Comp Biochem Physiolt D Genomics Proteomics 2014;10: 22-29.

32. Penglase S, Moren M, Hamre K. Lab animals: standardize the diet for zebrafish model. Nature 2012;491:333.

33. Kaushik S, Georga I, Koumoundouros G. Growth and body composition of zebrafish (Danio rerio) larvae fed a compound feed from first feeding onward: toward implications on nutrient requirements. Zebrafish 2011;8:87-95.

34. Lawrence C, Best J, James A, Maloney K. The effects of feeding frequency on growth and reproduction in zebrafish (Danio rerio). Aquaculture 2012;368:103-108.

35. Watts SA, Lawrence C, Powell M, D'Abramo LR. The vital relationship between nutrition and health in zebrafish. Zebrafish 2016;13(Suppl 1):S72-S76.

36. Fuentes-Appelgren P, Opazo R, Barros L, Feijoo CG, Urzua V, Romero J. Effect of the dietary inclusion of soybean components on the innate immune system in zebrafish. Zebrafish 2014;11:41-49.

37. Perera E, Yufera M. Soybean meal and soy protein concentrate in early diet elicit different nutritional programming effects on juvenile zebrafish. Zebrafish 2016;13:61-69.

38. Folch J, Lees M, Sloane Stanley G. A simple method for the isolation and purification of total lipides from animal tissues. J Biochem Physiol 1957;226:497-509.

39. Fowler LA, Dennis LN, Barry RJ, Powell ML, Watts SA, Smith DL Jr. In vivo determination of body composition in zebrafish (Danio rerio) by quantitative magnetic resonance. Zebrafish 2016;13:170-176.

40. Kimmel CB, Ballard WW, Kimmel SR, Ullmann B, Schilling TF. Stages of embryonic development of the zebrafish. Dev Dyn 1995;203:253-310.

41. Wilson JM, Bunte RM, Carty AJ. Evaluation of rapid cooling and tricaine methanesulfonate (MS222) as methods of euthanasia in zebrafish (Danio rerio). J Am Assoc Lab Anim Sci 2009;48:785-789.

42. Pinheiro J, Bates D, DebRoy S, Sarkar D, Team RC. nlme: Linear and Nonlinear Mixed Effects Models. R package version 31-131, 2016.

43. Hothorn T, Bretz F, Westfall P. Simultaneous inference in general parametric models. Biom J 2008;50:346-363.

44. Zeileis A, Kleiber C, Jackman S. Regression models for count data in R. J Stat Softw 2008;27:1-25.

45. Rigby RA, Stasinopoulos DM. Generalized additive models for location, scale, and shape (with discussion). Appl Stat 2005;54:507-554.

46. Rosenfeld J, Van Leeuwen T, Richards J, Allen D. Relationship between growth and standard metabolic rate: measurement artefacts and implications for habitat use and life-history adaptation in salmonids. J Anim Ecol 2015;84: 4-20.

47. National Research Council, ed. Nutrient Requirements of Fish and Shrimp. The National Academies Press, Washington, DC, 2011.

48. Spence R, Fatema MK, Ellis S, Ahmed ZF, Smith C. Diet, growth and recruitment of wild zebrafish in Bangladesh. J Fish Biol 2007;71:304-309.

49. Imrie D, Sadler KC. White adipose tissue development in zebrafish is regulated by both developmental time and fish size. Dev Dyn 2010;239:3013-3023.

50. Flynn E, Trent C, Rawls J. Ontogeny and nutritional control of adipogenesis in zebrafish (Danio rerio). J Lipid Res 2009;50:1641-1652.

51. Shiau S-Y, Lan C-W. Optimum dietary protein level and protein to energy ratio for growth of grouper (Epinephelus malabaricus). Aquaculture 1996;145:259-266.

52. Zhang NN, Ma QQ, Fan WJ, Xing Q, Zhao YL, Chen LQ, et al. Effects of the dietary protein to energy ratio on growth, feed utilization and body composition in Macrobrachium nipponense. Aquacult Nutr 2016:23:313-321.

53. Borengasser SJ, Zhong Y, Kang P, Lindsey F, Ronis MJJ, Badger TM, et al. Maternal obesity enhances white adipose tissue differentiation and alters genome-scale DNA methylation in male rat offspring. Endocrinology 2013;154: 4113-4125.

54. Johnston SL, Grune T, Bell LM, Murray SJ, Souter DM, Erwin SS, et al. Having it all: historical energy intakes do not generate the anticipated trade-offs in fecundity. Proc Biol Sci 2006;273:1369-1374.

55. Godfrey KM, Gluckman PD, Hanson MA. Developmental origins of metabolic disease: life course and intergenerational perspectives. Trends Endocrinol Metab 2010;21: 199-205.

56. Simpson SJ, Raubenheimer D. The Nature of Nutrition: A Unifying Framework from Animal Adaptation to Human Obesity. Princeton University Press, Princeton, New Jersey, 2012.

57. Hutchinson TH, Burden N. In response: benefits of the arrive guidelines for improving scientific reporting in ecotoxicology - an academic perspective. Environ Toxicol Chem 2015;34:2446-2448.

58. Meinelt BT, Schulz C, Wirth M, Kürzinger H, Steinberg C. Dietary fatty acid composition influences the fertilization rate of zebrafish (Danio rerio Hamilton-Buchanan). J Appl Ichthyol 1999;15:19-23.

59. Abayasekara DR, Wathes DC. Effects of altering dietary fatty acid composition on prostaglandin synthesis and fertility. Prostaglandins Leukot Essent Fatty Acids 1999;61: 275-287.

60. Mazorra C, Bruce M, Bell JG, Davie A, Alorend E, Jordan $\mathrm{N}$, et al. Dietary lipid enhancement of broodstock reproductive performance and egg and larval quality in Atlantic halibut (Hippoglossus hippoglossus). Aquaculture 2003; 227:21-33.

61. Izquierdo MS, Fernández-Palacios H, Tacon AGJ. Effect of broodstock nutrition on reproductive performance of fish. Aquaculture 2001;197:25-42.

62. Knight OM, Van Der Kraak G. The role of eicosanoids in 17alpha, 20beta-dihydroxy-4-pregnen-3-one-induced ovulation and spawning in Danio rerio. Gen Comp Endocrinol 2015;213:50-58.

63. Smith DL Jr., Barry RJ, Powell ML, Nagy TR, D’Abramo L, Watts SA. Dietary protein source influence on body size 
and composition in growing zebrafish. Zebrafish 2013;10: 439-446.

64. Siccardi AJ, Garris HW, Jones WT, Moseley DB, D'Abramo LR, Watts SA. Growth and survival of zebrafish (Danio rerio) fed different commercial and laboratory diets. Zebrafish 2009;6:275-280.

65. Gonzales JM. Preliminary evaluation on the effects of feeds on the growth and early reproductive performance of zebrafish (Danio rerio). J Am Assoc Lab Anim Sci 2012;51: 412-417.

66. Gonzales JM, Law SHW. Feed and feeding regime affect growth rate and gonadosomatic index of adult zebrafish (Danio rerio). Zebrafish 2013;10:532-540.

67. Monteiro JF, Martins S, Farias M, Costa T, Certal AC. The impact of two different cold-extruded feeds and feeding regimens on zebrafish survival, growth and reproductive performance. J Dev Biol 2018;6:15.
68. Markovich ML, Rizzuto NV, Brown PB. Diet affects spawning in zebrafish. Zebrafish 2007;4:69-74.

69. Barnard DE, Lewis SM, Teter BB, Thigpen JE. Open- and closed-formula laboratory animal diets and their importance to research. J Am Assoc Lab Anim Sci 2009;48:709_ 713.

Address correspondence to: Stephen A. Watts, BS Department of Biology University of Alabama at Birmingham Campbell Hall 374 1720 2nd Avenue South Birmingham, AL 35294-3360

E-mail: sawatts@uab.edu 